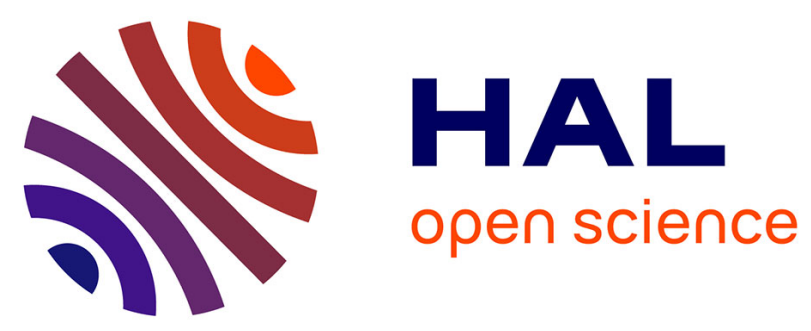

\title{
Dopaminergic denervation severity depends on COMT Val158Met polymorphism in Parkinson's disease
}

\author{
Julia Muellner, Iman Gharrad, Marie-Odile Habert, Aurélie Kas, \\ Jean-Baptiste Martini, Florence Cormier-Dequaire, Khadija Tahiri, Marie \\ Vidailhet, Niklaus Meier, Alexis Brice, et al.
}

\section{To cite this version:}

Julia Muellner, Iman Gharrad, Marie-Odile Habert, Aurélie Kas, Jean-Baptiste Martini, et al.. Dopaminergic denervation severity depends on COMT Val158Met polymorphism in Parkinson's disease. Parkinsonism \& Related Disorders, 2015, 21 (5), pp.471-476. 10.1016/j.parkreldis.2015.02.009 . hal-01120290

\section{HAL Id: hal-01120290 \\ https: / hal.sorbonne-universite.fr/hal-01120290}

Submitted on 25 Feb 2015

HAL is a multi-disciplinary open access archive for the deposit and dissemination of scientific research documents, whether they are published or not. The documents may come from teaching and research institutions in France or abroad, or from public or private research centers.
L'archive ouverte pluridisciplinaire HAL, est destinée au dépôt et à la diffusion de documents scientifiques de niveau recherche, publiés ou non, émanant des établissements d'enseignement et de recherche français ou étrangers, des laboratoires publics ou privés. 


\section{TITLE PAGE}

Article title: Dopaminergic denervation severity depends on COMT Val158Met polymorphism in Parkinson's disease

Authors' names and affiliations: Julia Muellner ${ }^{\mathrm{a}, \mathrm{b}}$, Iman Gharrad ${ }^{\mathrm{b}}$, Marie-Odile Habert ${ }^{\mathrm{d}}$, Aurélie $\mathrm{Kas}^{\mathrm{d}}$, Jean-Baptiste Martini ${ }^{d}$, Florence Cormier-Dequaire ${ }^{\mathrm{b}, \mathrm{c}}$, Khadija Tahiri ${ }^{\mathrm{b}}$, Marie Vidailhet $^{\mathrm{b}, \mathrm{c}}$, Niklaus Meier ${ }^{\mathrm{a}, \mathrm{b}}$, Alexis Brice ${ }^{\mathrm{b}}$, Michael Schuepbach ${ }^{\mathrm{a}, \mathrm{b}}$, Alain Mallet ${ }^{\mathrm{e}}$, Andreas Hartmann $^{\mathrm{b}, \mathrm{c}}$, Jean-Christophe Corvol ${ }^{\mathrm{b}, \mathrm{c}}$

a. Department of Neurology, Inselspital, Freiburgstrasse 100, 3010 Bern, Switzerland

b. Sorbonne University, UPMC Paris 06 UMR S 1127, and Inserm U 1127 and CIC 1422, and CNRS UR 7225, and ICM, 75013 Paris, France

c. AP-HP, Department of Neurology, Salpêtrière-Hospital, 75013 Paris, France

d. AP-HP, Department of Nuclear Medicine, Salpêtrière-Hospital, Sorbonne University, UPMC Paris 06, CNRS UMR 7371, INSERM U1146, 75013 Paris, France

e. Inserm U436, Laboratory of mathematical and statistical modelisation in biology and medicine, CHU Pitié-Salpêtrière, 91 bd de l'hôpital, 75634 Paris Cedex 13, France

\section{Corresponding author:}

Jean-Christophe Corvol, Clinical Investigation Center, Salpêtrière Hospital, 47, bd de I'hôpital, 75013 Paris, France,

Tel: +33 (0)157274000

Fax: +33 (0)15727 4027

e-mail: jean-christophe.corvol@psl.aphp.fr 
Word count:

Abstract: 245

Manuscript: 2468

Running title: COMT-Val158Met-SNP impacts on dopaminergic denervation

Key words: COMT, Parkinson's disease, dopaminergic denervation, motor symptoms, compensatory mechanism

Conflict of interest concerning the research related to the manuscript: None of the authors reports a conflict of interest.

Funding sources for study: French government's program "Investissement d'Avenir" (ANR10-IAIHU-06) 


\section{ABSTRACT}

Background: Catecholamine-O-methyl-tranferase (COMT) initiates dopamine degradation. Its activity is mainly determined by a single nucleotide polymorphism in the COMT gene (Val158Met, rs4680) separating high (Val/Val, COMT $T^{H H}$ ), intermediate (Val/Met, COMT $T^{H L}$ ) and low metabolizers (Met/Met, COMT ${ }^{L L}$ ). We investigated dopaminergic denervation in the striatum in PD patients according to COMT rs4680 genotype.

Methods: Patients with idiopathic PD were assessed for motor severity (UPDRS-III rating scale in OFF-state), dopaminergic denervation using [123I]-FP-CIT SPECT imaging, and genotyped for the COMT rs4680 enzyme. [123I]-FP-CIT binding potential (BP) for each voxel was defined by the ratio of tracer-binding in the region of interest (striatum, caudate nucleus and putamen) to that in a region of non-specific activity. Genotyping was performed using TaqMan® SNP genotyping assay. We used a regression model to evaluate the effect of COMT genotype on the BP in the striatum and its sub-regions.

Results: Genotype distribution was: 11 (27.5\%) COMT ${ }^{H H}, 26(65 \%)$ COMT $^{H L}$ and $3(7.5 \%)$ $C O M T^{L L}$. There were no significant differences in disease severity, treatments, or motor scores between genotypes. When adjusted to clinical severity, gender and age, low and intermediate metabolizers showed significantly higher rates of striatal denervation $\left(C O M T^{H L+L L} \mathrm{BP}=1.32+/-0.04\right)$ than high metabolizers $\left(C O M T^{H H}, B P=1.6+/-0.08\right.$; $F(1.34)=9.0, p=0.005)$. Striatal sub-regions showed similar results. BP and UPDRS-III motor scores $(r=0.44, p=0.04)(p<0.001)$ were highly correlated. There was a gender effect, but no gender-genotype interaction.

Conclusions: Striatal denervation differs according to COMT-Val158Met polymorphism. COMT activity may play a role as a compensatory mechanism in PD motor symptoms. 


\section{INTRODUCTION}

The underlying mechanism for the appearance of motor symptoms in Parkinson disease (PD) has long been identified as a progressive degeneration of dopaminergic neurons in the substantia nigra pars compacta (SNc). Motor symptoms appear when 40-60\% dopaminergic neurons have died, and when striatal denervation reaches about $80 \%[1,2]$. Compensating mechanisms are thus needed to delay the onset of motor symptoms which start when they are no longer sufficient to counterbalance striatal dopamine deficiency. In particular, an increase of dopamine turnover has been observed in animal models as well as in PD patients[3-5]. This increase can be partly explained by an increase in dopamine synthesis through an up-regulation of tyrosine hydroxylase $(\mathrm{TH})$ and aromatic acid decarboxylase $(A A D C)$ in the non-affected neurons[6-9], as well as a decrease of dopamine uptake by a down-regulation of dopamine transporter (DAT) expression[2, 5].

The catechol-O-methyl-transferase (COMT) enzyme initiates the degradation of brain synaptic dopamine levels by introducing a methyl-group from S-adenosylmethionin (SAM). Later, methylated dopamine is further degraded by monoamine oxidase (MAO). The human COMT gene (OMIM 116790) is located on chromosome 22q11.2. and contains two codominant alleles (Val158Met polymorphism, rs4680) which impact the enzyme activity[10]. The substitution of valine (Val) by methionine (Met) at codon 158 (Val158Met) in the membrane-bound isoform results in a trimodal distribution of high $\left(C O M T^{H H}\right)$, low (COMT $\left.T^{L L}\right)$ and intermediate $\left(C O M T^{H L}\right)$ enzymatic activity. COMT activity has been shown to be two- to four-fold higher in the liver and red blood cells of COMT $T^{H H}$ subjects than in those with the $C O M T^{L L}$ variant$[11,12]$. In a previous study, we found an association between the age at onset of motor symptoms in PD and the COMT rs4680, patients carrying $C O M T^{H H}$ and $C O M T^{H L}$ genotypes showing an earlier age of onset than patients with $C O M T^{L L}$ genotypes[13]. These results suggest that COMT activity may be involved in the 
mechanisms underlying the delay of motor symptoms in PD, a lower COMT activity acting as a compensatory mechanism of dopaminergic denervation.

The level of dopaminergic neuronal degeneration in the substantia nigra pars compacta can be indirectly measured by [123I]-FP-CIT Single Photon Emission Computed Tomography (SPECT). [123I]-FP-CIT binds to the dopamine transporter, the level of its binding capacity reduction in the striatum reflecting the amount of dopaminergic terminals denervation.

We hypothesized that COMT-activity in the striatum in PD patients contributes to the compensatory mechanisms that impact on clinical severity of motor symptoms in PD. As the extent of this activity is defined by COMT-genotype, we investigated whether, if normalized to motor severity, patients with low COMT-activity would show a higher level of dopaminergic denervation in the striatum measured by [123l]-FP-CIT than patients with high COMTactivity.

\section{METHODS}

\section{Subjects and study design}

The data in this study was obtained from a clinical trial investigating the effect of subcutaneous injections of bee venom in PD patients (clinicaltrials.gov, NCT01341431). Clinical and imaging data used in the study were obtained at the screening visit, before randomization and before any therapeutic intervention. Out of 50 patients who were seen for a pre-screening visit, 44 were included between April 2011 and October 2012 at the PitiéSalpêtrière Hospital (Paris, France). Inclusion criteria were age > 40, and idiopathic PD according to United Kingdom Parkinson's disease society brain bank criteria (UKPDSBB) with a Hoehn and Yahr score between 1.5 and 3 in the OFF-state. Exclusion criteria were magnet resonance imaging (MRI) indicating atypical or vascular PD, normal [123I]FP-CIT single photon emission computerized tomography (SPECT), and allergy to bee venom. The study was submitted to the regulatory authority and the local ethics committee. Written informed consent was obtained by all subjects before being included in the study. 


\section{Clinical data}

Clinical characteristics were obtained for each patient including medical history, drug history and current medication, Mini-Mental State Examination (MMSE), Frontal Assessment Battery (FAB), Unified Parkinson disease Rating Scale (UPDRS) part I-IV, Hoehn and Yahr stage, onset of PD symptoms and time of PD diagnosis. The UPDRS motor scale (part III) was addressed at the screening visit to patients in the OFF state, i.e. in the morning, after withdrawal of dopaminergic drugs for at least 12 hours for L-DOPA, and 48 hours for dopamine agonists and rasagiline. A [123I]-FP-CIT SPECT scan was performed 1-25 days before or 3-17 days after the screening visit. The examining neurologist and the patient were blinded for COMT-genotype and SPECT evaluations.

\section{Dopamine transporter imaging}

SPECT studies were performed in all subjects using a triple-head camera equipped with low energy, high resolution parallel hole collimators (Irix, Philips), 3 hours after injection of 185 MBq (range 165-188 MBq) of [123I]-FP-CIT. Thyroid uptake was blocked before the scan by administration of potassium perchlorate (400 mg orally). One hundred and twenty projections were acquired during 30 minutes in a $128 \times 128$ matrix. Projections were reconstructed using an iterative algorithm, post-filtered (low pass filter: order $=4$, cut-off frequency $=0.35 \mathrm{~cm}-1$ ), then corrected for attenuation using the Chang method[14] $(\mu=0.12 \mathrm{~cm}-1)$.

All reconstructed volumes were converted from DICOM to NIFTI format. Parametric images of binding potential (BP) were computed from the reconstructed [123I]-FP-CIT volumes using the Anatomist and Brainvisa software packages (http://brainvisa.info/). For each FP-CIT study, a volume of interest was drawn within the occipital cortex to obtain non-specific activity, and $\mathrm{BP}$ was calculated in each voxel using the following formula: (mean voxel activity / mean occipital activity) minus 1 . The resulting parametric volumes were then spatially normalized to the Montreal Neurological Institute (MNI) space with the Statistical Parametric Mapping software (SPM8, Welcome Department of Cognitive Neurology, University College, London) 
using a custom [123I]-FP-CIT template[15]. Next, BP was estimated for each parametric image in a standard set of specific volumes of interest (VOI), i.e. right and left caudate nuclei and putamens. These VOI were manually delineated on the MNI single subject MRI by AK in a previous work[15].

\section{Genotyping}

DNA was extracted from peripheral blood lymphocytes using a salting out procedure and stored at $-80^{\circ} \mathrm{C}$. The rs 4680 was analyzed using an a llelic discrimination Taqman assay (ABI PRISM 7900 sequence detection system). The 5' nuclease activity of taq DNA polymerase was used to detect the fluorescent reporter signal generated after the polymerase chain reaction (PCR). As positive controls, two samples of DNA with the COMTHH, COMTHL, and COMTLL genotyped previously confirmed by sequencing were processed concomitantly for each assay. Patients signed a specific informed consent form for the genetic analysis.

\section{Statistics and Analysis}

Clinical characteristics were compared between genotypes using the non-parametric MannWhitney test and the Fisher Exact test. Gender differences were compared using the MannWhitney test. A general multiple regression model was used to analyze the effect of the COMT genotype (COMT $\left.T^{H H}, C O M T^{H L+H L}\right)$ on nigrostriatal denervation, adjusted for UPDRS-III score, age and sex. Univariate correlation between BP, UPDRS III and age was performed using the Spearman Rank Correlation test. A non-corrected threshold of $p<0.05$ was defined for significance. All statistical analyses were performed using Statistica 9.1 software (Statsoft, Maison Alfort, France).

\section{RESULTS}

\section{Patient characteristics}


Among the 44 patients screened, 4 were excluded from the analysis: 2 patients had vascular abnormalities on brain MRI, 1 patient had a normal [123I]-FP-CIT SPECT, and 1 patient refused to participate in the genetic study. The distribution of the Val158Met COMT polymorphism genotype for the remaining 40 patients, all of Caucasian origin, was in slight Hardy-Weinberg disequilibrium ( $p$-value =0.03): $11(27.5 \%) C O M T^{H H}, 26(65 \%) C O M T^{H L}$ and $3(7.5 \%) C O M T^{L L}$. Subjects with $C O M T^{H L}$ and $C O M T^{L L}$ were considered as a group for further analyses since there was only 3 patients with the COMT $T^{L L}$ genotype. The clinical characteristics of these patients are summarized in Table 1. There were no significant differences between age, gender, age at onset, disease duration or motor severity (UPDRS III) between genotypes. The number of patients on levodopa and/or dopamine agonists was similar between the COMTHH and the COMTHL+LL groups (respectively 10/11 (91\%) and $24 / 29(83 \%)$ on levodopa, $p=0.46 ; 7 / 11(64 \%)$ and $22 / 29(76 \%), p=0.35)$, as well as and the current total levodopa equivalent daily doses did not differ between groups (table 1).

Table 1

\section{Total striatal dopaminergic denervation}

The BP in the total striatum had an average of 1.38 (+/- 0.34 , standard deviation) with a range from 0.62 to 2.21 . BP in the putamen $(1.24+/-0.32)$ was significantly lower than in the caudate nucleus $(1.52+/-0.39, \mathrm{p}<0.001)$. BP in the total striatum was significantly different between genotypes when adjusted to clinical severity (UPDRS III), gender and age $(F(1,34)=$ 9.0, $\mathrm{p}=0.005$, Table 2). Low and intermediate metabolizers (COMT $T^{H L+L L}$ ) showed a higher rate of denervation than high metabolizers $\left(C O M T^{H H}\right)$ (Figure 1). By considering the different sub-regions of the striatum, we found similar results for the caudate nucleus $(F(1,34)=8.6$, $p=0.006$, Figure $1 \mathrm{~B}$ and Table 2$)$ and the putamen $(F(1,34)=7.0, p=0.01$, Figure $1 \mathrm{C}$ and Table 2). Dopaminergic denervation was higher in low and intermediate metabolizers as compared to high metabolizers for both the caudate nucleus and the putamen. The LEDD had no significant effect when introduced as a cofactor in the model. 


\section{Other factors associated with dopaminergic denervation}

There was a significant independent correlation between BP in the total striatum and clinical motor symptoms (UPDRS III: $\mathrm{p}=0.04, \mathrm{r}=-0.44$ ) (Table 3, Figure 2). This correlation was significant for both the putamen and the caudate nucleus denervation $(r=-0.43, p=0.04$, and $r=-0.44, p=0.04$ respectively). In accordance with previous studies[16], we also found an independent effect of gender (Table 3). In our study, BP in women was $1.59+/-0.30$ as compared to $1.19+/-0.27$ in men $(p<0.001)$. However, there was no significant gendergenotype interaction in our model $(p=0.33)$.

Table 3

\section{DISCUSSION}

We observed differences in dopaminergic denervation between Val158Met COMT genotypes in PD patients when adjusted for clinical motor symptom severity (UPDRS III score). Our results show that, for similar motor severity, patients with a COMT $T^{H L+L L}$ genotype, associated with a lower COMT activity, have a greater extent of nigrostriatal denervation than those with a COMT genotype associated with a higher COMT activity $\left(C O M T^{H H}\right)$. This result suggests that patients with a lower COMT-activity are able to compensate the neuronal loss to a greater extent by increasing dopamine bioavailability in the striatum.

The Val158Met COMT polymorphism has a functional impact on enzyme activity in the periphery in healthy subjects[12] as well as in PD patients[17, 18]. A PET study recently confirmed that the Val158Met polymorphism also modifies dopamine turnover in the prefrontal cortex in PD patients [19].. Indeed, this polymorphism has been associated with prefrontal cortex function, such as working memory, in several studies performed in healthy controls[20] as well as in PD [21]. However, the role of the COMT Val158Met polymorphism 
on motor symptoms and on the dopamine turnover in the striatum remains controversial. Indeed, by contrast to the prefrontal cortex, uptake of dopamine by the DAT is the most effective mechanism in the striatum, where the contribution of the COMT remains secondary under normal conditions. Although COMT is expressed in the striatum, inhibition of its activity in rodents either via pharmacological intervention or via disruption of the COMT gene in rodents reveals minor change in their motor behaviour and brain dopamine levels [22]. In accordance with this finding, a study analyzing D2-receptor binding (an indirect measure of endogenous striatal dopamine bio-availability) failed to demonstrate a significant difference between Val158Met genotypes in healthy subjects[20]. However, although COMT deficiency does not alter dopamine concentrations in the striatum, its metabolism is changed as demonstrated by a dramatic increase of DOPAC levels in the dorsal striatum of mice lacking COMT activity [23, 24]. Higher levels of DOPAC in the striatum of patients with the COMTHL+LL genotype could partly explain the motor compensation observed in our study since intracerebral administration of DOPAC in the brain in rats has been shown to cause a modest increase of behavioural activity and stereotypy in rats [25]. A better explanation would be that, in the pathological condition of PD in which dopaminergic terminals degenerate and the DAT expression is dramatically decreased in the striatum, the COMT becomes the major pathway to control dopamine extracellular levels. The effect of the disruption of the COMT gene after dopaminergic denervation has not been studied yet in knockout mice. However, the pharmacological inhibition of DAT in mice lacking COMT resulted in higher dopamine levels in the striatum although this effect increase had little effects on behaviour $[23,26]$.

The hypothesis that COMT activity participates in the dopamine bioavailability in the dorsal striatum, is also supported by previous findings showing that PD patients with the COMT $T^{H H}$ genotype have an earlier age of disease onset as compared to $C O M T^{L L}[13]$. This result is consistent with our study suggesting that patients with a higher COMT activity (COMT $\left.T^{H H}\right)$ have lower compensatory capacity than patients with a lower COMT activity $\left(C O M T^{+1 L+L L}\right)$. 
Importantly, this effect is unlikely to be related to a role of the COMT on striatal dopaminergic denervation since no association has been found between the COMT Val158Met polymorphism and PD in the Caucasian population [27]. A potential role of the COMT as a susceptibility factor for PD in patients with other ethnic background, particularly in the Asian population, is still controversial $[27,28]$. Another indirect evidence of a potential role of the COMT activity in the striatum is the association that has been found between the low-activity genotype of theVal158Met COMT polymorphism and an increased risk of levodopa-induced dyskinesia in PD [29].

Interestingly, a gender dimorphism has been found for the Val158Met-polymorphism effect in mice [30] as well as on the age of onset in PD patients[13] which remains to be understood. In this study, we did not find an interaction between Val158Met COMT polymorphisms and gender for nigrostriatal denervation adjusted on motor severity, but the sample size was too small to properly evaluate this effect.

Our study has some limitations. As PD patients included in this study were more advanced in the course of their disease, this explains the greater extent of dopaminergic denervation in comparison to previous studies in de novo PD patients[31]. In addition, we cannot rule out a residual treatment effect although UPDRS III testing and [123I]-FP-CIT imaging were performed in the OFF-state after a period of washout taking into account the pharmacology of anti-parkinsonian drugs[32]. The robust correlation between motor state (UPDRS part III) and dopamine denervation suggests that the OFF state indeed reflects the motor status of the patients. Our study is also limited by the relative small sample size and will have to be replicated in a larger population of de novo, drug-naïve, PD patients.

\section{CONCLUSION}

We showed that genotypes associated with low COMT activity is correlated with a greater extent of nigrostriatal denervation when adjusted to UPDRSIII-score. How COMT activity influences compensatory mechanisms of motor symptoms during the course of PD and whether it influences disease progression remains to be determined. 


\section{ACKNOWLEDGEMENT}

We would like to thank the nursing staff of the Center for Clinical Investigation, PitiéSalpêtrière Hospital, Paris, France and the Department of Genetic Analysis for their kind support. The research leading to these results was funded in part by the French government programme "Investissement d'Avenir" (ANR-10-IAIHU-06). 


\section{Author Roles}

1) Research project:

Design: Jean-Christophe Corvol

Organization: Jean-Christophe Corvol, Julia Muellner

Execution:

a) Clinical examination: Julia Muellner

b) Recruitment of patients: Julia Muellner, Andreas Hartmann, Michael Schuepbach, Niklaus

Meier, Marie Vidailhet, Jean-Christophe Corvol

c) Genetic analysis: Khadija Tahiri, Florence Cormier, Alexis Brice,

d) Acquisition and/or analysis of SPECT data: Marie-Odile Habert, Iman Gharrad, Aurélie Kas, Jean-Baptiste Martini

2) Statistical Analysis:

Design: Jean-Christophe Corvol

Execution: Iman Gharrad, Jean-Christophe Corvol

Review and Critique: Alain Mallet, Jean-Christophe Corvol;

3) Manuscript:

Writing of the first draft: Julia Muellner

Review and Critique: all authors

\section{Financial Disclosures}

Julia Muellner has received travel grants from Ipsen Pharma and from COST Action.

Marie-Odile Habert states to be a consultant for GE Healthcare and NICESOFT companies.

Iman Gharrad confirms nothing to disclose.

Aurélie Kas confirms nothing to disclose.

Jean-Baptiste Martini confirms nothing to disclose.

Florence Cormier-Dequaire confirms nothing to disclose. 
Khadija Tahiri confirms nothing to disclose.

Marie Vidailhet has been an invited speaker at ENS, EFNS and MDS International meetings. She is on the scientific advisory board of Novartis and Merz. She has received unrestricted research grants from DHOS-INSERM and ANR (French National Institutes) and from AMADYS and Alliance France Dystonie (patient associations).

Niklaus Meier received consultant's honoraria from Merck Serono and travel grants from Ipsen Pharma.

Alexis Brice received honoraria from the Wolfson Foundation for reviewing the scientific project. He also received honoraria from Lundbeck for giving a talk.

Michael Schuepbach reports receiving consulting fees and lecture fees from Medtronic and Aleva, grant support from Ipsen and Actelion for organization of a lecture series on movement disorders. Furthermore, he was serving as an expert witness for Lundbeck and received congress fees and travel reimbursements from Boston Scientific.

Alain Mallet confirms nothing to disclose.

Andreas Hartmann confirms nothing to disclose.

Jean-Christophe Corvol declares honoraria from Lundbeck, grants from Sanofi-Aventis, the Michael J Fox Foundation, the French ministry of Health (PHRC), and the Institut National de la Santé et de la Recherche Médicale (INSERM). 


\section{References}

[1] Bezard E, Dovero S, Prunier C, Ravenscroft P, Chalon S, Guilloteau D, et al. Relationship between the appearance of symptoms and the level of nigrostriatal degeneration in a progressive 1-methyl-4-phenyl-1,2,3,6-tetrahydropyridine-lesioned macaque model of Parkinson's disease. J Neurosci. 2001;21:6853-61. [2] Agid Y. Parkinson's disease: pathophysiology. Lancet. 1991;337:1321-4.

[3] Goldberg NR, Haack AK, Lim NS, Janson OK, Meshul CK. Dopaminergic and behavioral correlates of progressive lesioning of the nigrostriatal pathway with 1-methyl-4-phenyl1,2,3,6-tetrahydropyridine. Neuroscience. 2011;180:256-71.

[4] Pifl C, Hornykiewicz O. Dopamine turnover is upregulated in the caudate/putamen of asymptomatic MPTP-treated rhesus monkeys. Neurochem Int. 2006;49:519-24. [5] Nandhagopal R, Kuramoto L, Schulzer M, Mak E, Cragg J, McKenzie J, et al. Longitudinal evolution of compensatory changes in striatal dopamine processing in Parkinson's disease. Brain. 2011;134:3290-8.

[6] Bezard E, Gross CE. Compensatory mechanisms in experimental and human parkinsonism: towards a dynamic approach. Prog Neurobiol. 1998;55:93-116.

[7] Zigmond MJ, Abercrombie ED, Berger TW, Grace AA, Stricker EM. Compensations after lesions of central dopaminergic neurons: some clinical and basic implications. Trends Neurosci. 1990;13:290-6. [8] Zigmond MJ, Acheson AL, Stachowiak MK, Stricker EM. Neurochemical compensation after nigrostriatal bundle injury in an animal model of preclinical parkinsonism. Arch Neurol. 1984;41:856-61.

[9] Lee CS, Samii A, Sossi V, Ruth TJ, Schulzer M, Holden JE, et al. In vivo positron emission tomographic evidence for compensatory changes in presynaptic dopaminergic nerve terminals in Parkinson's disease. Ann Neurol. 2000;47:493-503.

[10] Floderus $Y$, Wetterberg $L$. The inheritance of human erythrocyte catechol-Omethyltransferase activity. Clin Genet. 1981;19:392-5.

[11] Lotta T, Vidgren J, Tilgmann C, Ulmanen I, Melen K, Julkunen I, et al. Kinetics of human soluble and membrane-bound catechol O-methyltransferase: a revised mechanism and description of the thermolabile variant of the enzyme. Biochemistry. 1995;34:4202-10.

[12] Lachman HM, Papolos DF, Saito T, Yu YM, Szumlanski CL, Weinshilboum RM. Human catechol-O-methyltransferase pharmacogenetics: description of a functional polymorphism and its potential application to neuropsychiatric disorders. Pharmacogenetics. 1996;6:24350 .

[13] Klebe S, Golmard JL, Nalls MA, Saad M, Singleton AB, Bras JM, et al. The Val158Met COMT polymorphism is a modifier of the age at onset in Parkinson's disease with a sexual dimorphism. J Neurol Neurosurg Psychiatry. 2013;84:666-73.

[14] Chang T, Diab RH, Clark JW, Jr., Mawlawi OR. Investigating the use of nonattenuation corrected PET images for the attenuation correction of PET data. Medical physics.

2013;40:082508 
[15] Kas A, Payoux P, Habert MO, Malek Z, Cointepas Y, El Fakhri G, et al. Validation of a standardized normalization template for statistical parametric mapping analysis of 123I-FPCIT images. J Nucl Med. 2007;48:1459-67.

[16] Haaxma CA, Bloem BR, Borm GF, Oyen WJ, Leenders KL, Eshuis S, et al. Gender differences in Parkinson's disease. J Neurol Neurosurg Psychiatry. 2007;78:819-24.

[17] Maltete D, Cottard AM, Mihout B, Costentin J. Erythrocytes catechol-o-methyl transferase activity is up-regulated after a 3-month treatment by entacapone in parkinsonian patients. Clin Neuropharmacol. 2011;34:21-3.

[18] Corvol JC, Bonnet C, Charbonnier-Beaupel F, Bonnet AM, Fievet MH, Bellanger A, et al. The COMT Val158Met polymorphism affects the response to entacapone in Parkinson's disease: a randomized crossover clinical trial. Ann Neurol. 2011;69:111-8.

[19] Hirvonen MM, Nagren K, Rinne JO, Pesonen U, Vahlberg T, Hagelberg N, et al. COMT Val158Met genotype does not alter cortical or striatal dopamine D2 receptor availability in vivo. Mol Imaging Biol. 2010;12:192-7.

[20] Mier D, Kirsch P, Meyer-Lindenberg A. Neural substrates of pleiotropic action of genetic variation in COMT: a meta-analysis. Mol psychiatry. 2010;15:918-27.

[21] Williams-Gray CH, Hampshire A, Robbins TW, Owen AM, Barker RA. Catechol Omethyltransferase Val158Met genotype influences frontoparietal activity during planning in patients with Parkinson's disease. J Neurosci. 2007 May 2;27(18):4832-8.

[22] Gogos JA, Morgan M, Luine V, Santha M, Ogawa S, Pfaff D, et al. Catechol-Omethyltransferase-deficient mice exhibit sexually dimorphic changes in catecholamine levels and behavior. Proc Natl Acad Sci U S A. 1998 Aug 18;95(17):9991-6.

[23] Huotari M, Santha M, Lucas LR, Karayiorgou M, Gogos JA, Männistö PT. Effect of dopamine uptake inhibition on brain catecholamine levels and locomotion in catechol-Omethyltransferase-disrupted mice. J Pharmacol Exp Ther. 2002 Dec;303(3):1309-16.

[24] Tammimäki A, Käenmäki M, Kambur O, Kulesskaya N, Keisala T, Karvonen E, et al. Effect of S-COMT deficiency on behavior and extracellular brain dopamine concentrations in mice. Psychopharmacology (Berl). 2010 Sep;211(4):389-401.

[25] Nakazato T, Akiyama A, Behavioral activity and stereotypy in rats induced by L-DOPA metabolites: a possible role in the adverse effects of chronic L-DOPA treatment of Parkinson's disease. Brain Res. 2002 Mar 15;930(1-2):134-42.

[26] Huotari M, García-Horsman JA, Karayiorgou M, Gogos JA, Männistö PT. Damphetamine responses in catechol-O-methyltransferase (COMT) disrupted mice. Psychopharmacology (Berl). 2004 Feb;172(1):1-10.

[27] Lechun L, Yu S, Pengling H, Changqi H. The COMT Val158Met polymorphism as an associated risk factor for Parkinson's disease in Asian rather than Caucasian populations. Neurol India. 2013 Jan-Feb;61(1):12-6. 
[28] Jiménez-Jiménez FJ, Alonso-Navarro H, García-Martín E, Agúndez JA. COMT gene and risk for Parkinson's disease: a systematic review and meta-analysis. Pharmacogenet Genomics. 2014 Jul;24(7):331-9. [29] de Lau LM, Verbaan D, Marinus J, Heutink P, van Hilten JJ. Catechol-O-methyltransferase Val158Met and the risk of dyskinesias in Parkinson's disease. Mov Disord. 2012;27:132-5.

[30] Chen J, Lipska BK, Halim N, Ma QD, Matsumoto M, Melhem S, et al. Functional analysis of genetic variation in catechol-O-methyltransferase (COMT): effects on mRNA, protein, and enzyme activity in postmortem human brain. Am J Hum Genet. 2004 Nov;75(5):807-21.

[31] Ichise M, Kim YJ, Ballinger JR, Vines D, Erami SS, Tanaka F, et al. SPECT imaging of pre- and postsynaptic dopaminergic alterations in L-dopa-untreated PD. Neurology. 1999;52:1206-14.

[32] Storch A, Wolz M, Beuthien-Baumann B, Lohle M, Herting B, Schwanebeck U, et al. Effects of dopaminergic treatment on striatal dopamine turnover in de novo Parkinson disease. Neurology. 2013;80:1754-61. 


\section{Figures}

\section{Figure 1}

Title: Binding Potential in the Striatum, Putamen and Caudate nucleus

Legend: Binding potential (BP) in the total striatum (A), the caudate $(B)$, and the putamen $(C)$ in patients with $\mathrm{COMTHH}$ and $\mathrm{COMTHH}+\mathrm{HL}$ genotypes. Values are means (black squares) +/- SD. ${ }^{* *} p<0.001,{ }^{*} p<0.01$, effect of the COMT genotype on BP by using a multiple regression model including UPDRS-III score, age and sex as covariates.

Figure 2

Title: Correlation between nigrostriatal denervation and UPDRS III

Legend: Binding potential (BP) as a function of UPDRS III score. $p=0.04, r=0.44$, Spearman rank correlation test. 
Table 1

Title: Patient characteristics

\begin{tabular}{lcc}
\hline Genotype & COMT $^{+H}(\mathrm{n}=11)$ & COMT $^{\mathrm{HL}+L L}(\mathrm{n}=29)$ \\
\hline Age, years & $63(54-78)$ & $63(44-80)$ \\
\hline Age at onset, years & $56(49-74)$ & $54(36-75)$ \\
\hline Sex ratio, m/f & $7 / 4$ & $14 / 15$ \\
\hline UPDRS III & $30(10-42)$ & $26(6-59)$ \\
\hline Levodopa daily & $300(0-1132)$ & $400(0-1132)$ \\
doses, mg/day & & \\
\hline $\begin{array}{l}\text { Dopamine agonists } \\
\text { daily dose, LEDD, } \\
\text { mg/day }\end{array}$ & $120(0-371)$ & \\
\hline Total LEDD & & \\
\hline
\end{tabular}

Legend: LEDD: levodopa equivalent daily dose; values are median (range). 
Table 2

Title: Striatal denervation in the striatum according to COMT genotypes

\begin{tabular}{llll}
\hline & Striatum & Putamen & Caudate nucleus \\
\hline COMT $^{H H}$ & $1.5+/-0.1$ & $1.4+/-0.1$ & $1.6+/-0.1$ \\
\hline COMT $^{\text {TL+LL }}$ & $1.3+/-0.06$ & $1.2+/-0.05$ & $1.5+/-0.06$ \\
\hline$p$-value & 0.005 & 0.006 & 0.01 \\
\hline
\end{tabular}

Legend: Values are mean +/- standard errors. P-value: regression analysis of the COMTgenotype effect on binding potential (BP) in the total striatum, putamen, and caudate nucleus, adjusted to UPDRS part III, age and gender. 
Table 3

Title: Effects of Age, COMT genotype, UPDRS-III score and gender on striatal denervation

\begin{tabular}{lcccccc}
\hline & Striatum & \multicolumn{2}{l}{ Caudate nucleus } & \multicolumn{2}{l}{ Putamen } \\
& $\mathrm{F}$ & $\mathrm{p}$ & $\mathrm{F}$ & $\mathrm{p}$ & $\mathrm{F}$ & $\mathrm{p}$ \\
\hline Age & 3.0 & 0.09 & 3.3 & 0.08 & 2.1 & 0.16 \\
\hline UPDRS III & 5.6 & 0.02 & 5.2 & 0.03 & 5.3 & 0.03 \\
\hline Genotype & 9.0 & 0.005 & 8.6 & 0.006 & 7.0 & 0.01 \\
\hline Gender & 23.2 & 0.0003 & 33.9 & $<0.001$ & 10.1 & 0.003 \\
\hline Genotype*gender & 1.0 & 0.33 & 2.6 & 0.12 & 0.02 & 0.90 \\
interaction & & & & & & \\
\hline
\end{tabular}

Legend: Regression analysis parameters for age, UPDRS-III score, COMT-genotype, gender, and genotype* gender interaction on nigrostriatal denervation (BP) in the total striatum, the caudate nucleus, and the putamen. 

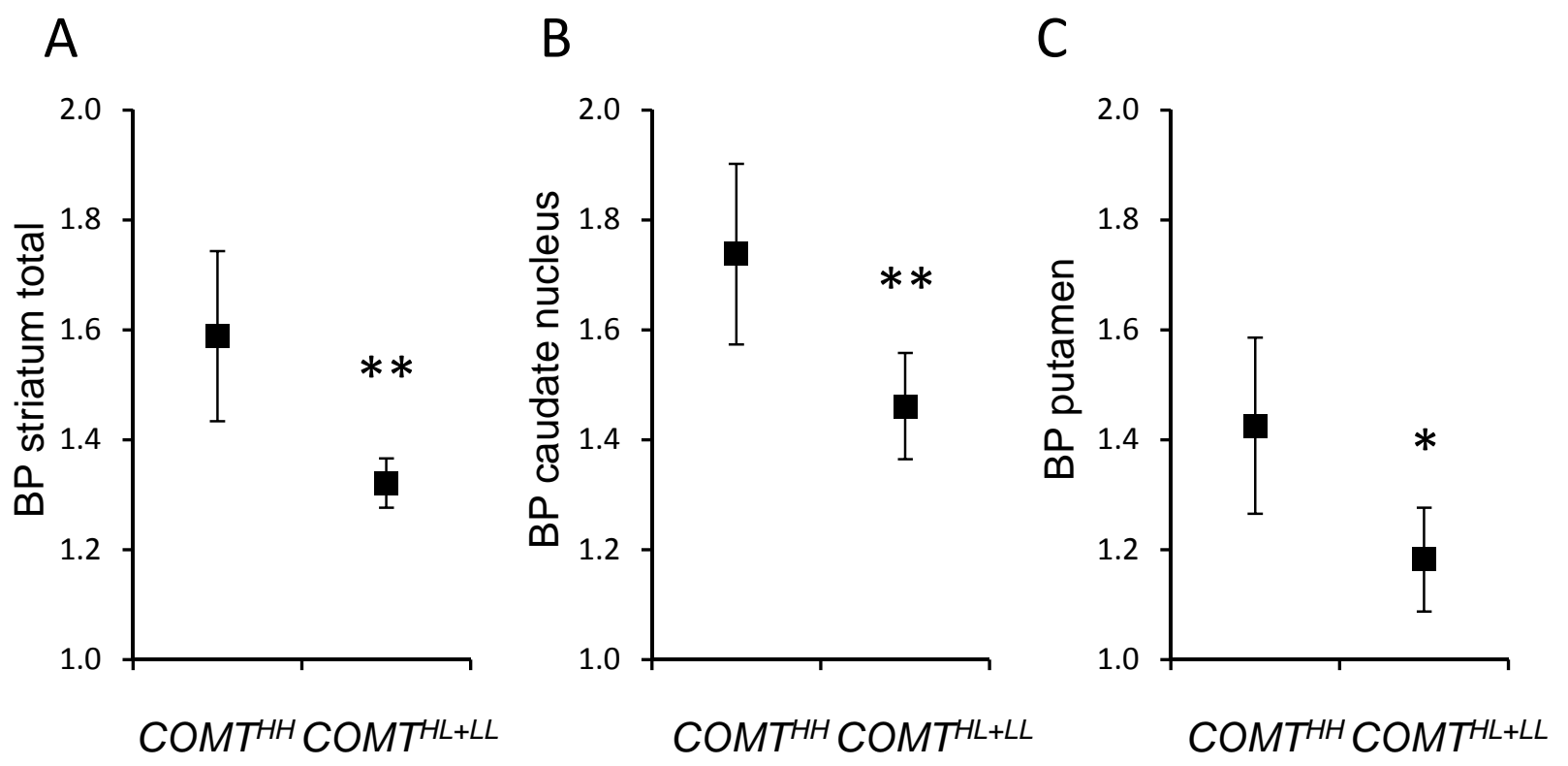


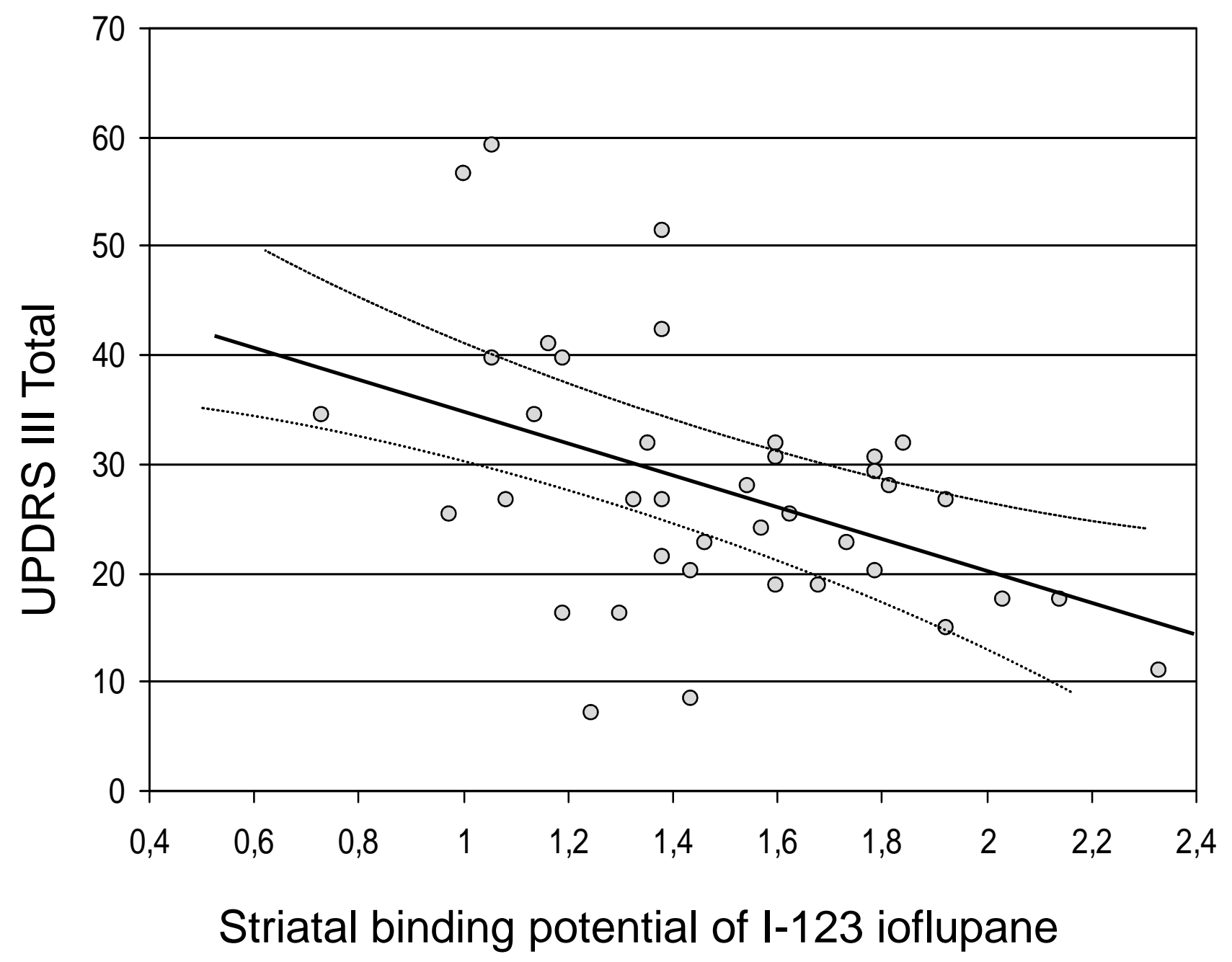


Highlights:

- We performed a UPDRSIII-score and [123I]-FP-CIT SPECT imaging on 40 PD patients

- All patients were genotyped for the COMT-Val158Met polymorphism

- Adjusted to UPDRSIII-score PD patients had different levels of striatal denervation

- We showed that the COMT-genotype impacts on clinical severity of motor symptoms

- We conclude that COMT enzyme activity may act as a compensatory mechanism in PD 